\title{
Remote ischemic preconditioning in liver graft viability
}

\section{Preacondicionamiento isquémico remoto sobre viabilidad del injerto hepático}

\author{
Paula Cordero-Pérez¹, Marco Hernández-Guedea², Julio C. Jiménez-Pérez¹, Linda Muñoz-Espinosa', \\ Edelmiro Pérez-Rodríguez ${ }^{2}$ and Homero A. Zapata-Chavira ${ }^{2 *}$ \\ ${ }^{1}$ Department of Internal Medicine; ${ }^{2}$ Transplantation Department. Universidad Autónoma de Nuevo León, Hospital Universitario Dr. José E. González, \\ Monterrey, Nuevo Leon, Mexico
}

\begin{abstract}
Background: Remote ischemic preconditioning (RIP) in liver transplantation has been suggested experimentally as a strategy to reduce ischemia-reperfusion injury. Objective: Evaluate the effect of RIP on liver graft in cadaveric donors and the impact of various inflammatory mediators in this process. Method: Ten liver transplantation recipients, 5 controls and 5 RIP were made in the cadaver donors by applying a pneumatic tourniquet in the upper third of both thighs for a period of 10 minutes followed by 10 minutes reperfusion. The determination of interleukine (IL)-1, IL-6, tumor necrosis factor alpha (TNF- $\alpha$ ), vascular endothelial growth factor (VEGF), intracellular adhesion molecule (ICAM)-1 was performed as well as hematological and biochemical parameters at various stages of liver transplantation. Results: Significant increase of aspartate aminotransferase (AST), alanine aminotransferase (ALT) and alkaline phosphatase in the early stages of post-liver transplantation were observed, after 72 hours subjects who received liver transplantation subjected to RIP they showed a better response, which was also evident in platelet recovery, which persisted until phase 3 months in this group. IL-6 appears to participate in the early stages of the ischemia-reperfusion injury, contrary to TNF- $\alpha$ that increases until day 7 while ICAM-1 was increased in all phases. Conclusions: In this pilot study the PIR decreased the damage by ischemia-reperfusion injury, although the greatest effect was observed after 72 hours.
\end{abstract}

Key words: Ischemia/reperfusion. Liver transplantation. Ischemic preconditioning. Remote ischemic preconditioning.

\section{Resumen}

Antecedentes: El preacondicionamiento isquémico remoto (PIR) en trasplante hepático ha sido sugerido en el ámbito experimental como estrategia para disminuir la lesión por isquemia- reperfusión. Objetivo: Evaluar el efecto del PIR sobre el injerto hepático en donante cadáver y el impacto de diversos mediadores inflamatorios en este proceso. Método: Se incluyeron 10 receptores de trasplante hepático, 5 controles y 5 con PIR, el cual fue realizado en los donantes cadavéricos mediante la aplicación de un torniquete neumático en ambos muslos por 10 minutos seguido de 10 minutos de reperfusión. Se determinaron interleucina (IL)-1, IL-6, factor de necrosis tumoral alfa (FNT- $\alpha$ ), factor de crecimiento endotelial vascular (FCEV) y molécula de adhesión intracelular (ICAM)-1, parámetros hematológicos y bioquímicos en diversas fases del trasplante hepático. Resultados: Se observó un aumento significativo de la aspartato aminotransferasa (AST), la alanino aminotransferasa $(A L T)$ y la fosfatasa alcalina en las fases tempranas tras el trasplante hepático, y a las 72 horas los sujetos con PIR mostraron mejor respuesta, con recuperación de plaquetas, que persistió hasta los 3 meses en este grupo. La IL-6

\footnotetext{
Correspondence:

*Homero A Zapata-Chavira

Gonzalitos 235, Col. Mitras Centro, C.P. 64460, Date of reception: 12-04-2018

Monterrey, N.L., México Date of acceptance: 15-05-2018

E-mail: homero_zapata@yahoo.com

DOI: $10.24875 / C I R U E . M 18000083$

Cir Cir. 2018;86(6):659-667

Contents available at PubMed

www.cirugiaycirujanos.com

0009-7411/@ 2018 Academia Mexicana de Cirugía. Published by Permanyer. This is an open access article under the terms of the CC BY-NC-ND license (http://creativecommons.org/licenses/by-nc-nd/4.0/).
} 
participa en las fases tempranas de la lesión por isquemia- reperfusión, contrario al FNT- $\alpha$, que se incrementa hasta el día 7 , mientras que la ICAM-1 aumentó en todas las fases. Conclusiones: En este estudio piloto, el PIR disminuyó el daño por lesión por isquemia- reperfusión, aunque el mayor efecto se observó después de 72 horas.

Palabras clave: Isquemia/reperfusión. Trasplante hepático. Preacondicionamiento isquémico. Preacondicionamiento isquémico remoto.

\section{Introduction}

Liver transplantation is considered the only treatment option for terminal phase liver diseases; however, there are various mechanisms that can harm the organ to be transplanted. Ischemia-reperfusion damage is a cell damage increase phenomenon in an ischemic organ after oxygen flow restoration'. In the liver, ischemia-reperfusion damage is associated with transplantation, resection or vascular reconstruction liver surgery, and trauma².

Ischemia-reperfusion injury is a complex and multifactorial process where a series of cellular and molecular changes is produced, such as activation of the inflammatory cascade, oxidative stress, energy depletion and an ionic and $\mathrm{pH}$ imbalance which culminates in cell function deterioration and gives rise to extensive tissue damage ${ }^{3-5}$. Ischemia-reperfusion injury is one of the main causes of initial function delay and liver graft failure.

Numerous strategies have been used to decrease ischemia-reperfusion damage in various experimental models, but only some of these have shown efficacy in human studies. In 2003, Selzner et al. ${ }^{6}$ classified the procedures to reduce ischemia-reperfusion injury in pharmacological, surgical (preconditioning ischemic, remote ischemic preconditioning [RIP]) and gene therapy procedures.

Currently, many investigations in the transplantation field are aimed at understanding the mechanisms involved in ischemia-reperfusion injury; the goal is to develop new therapeutic strategies that allow reducing this lesion and thus minimize the risk of graft dysfunction, but none of the three strategies has turned out to be completely efficacious in the prevention of ischemiareperfusion injury associated with transplantation $n^{7-9}$.

Within the pathophysiology of RIP, various involved mechanisms have been described, including $\mathrm{Na} / \mathrm{K}$ pump failure, calcium concentration increase, free radical formation, malondialdehyde formation and antioxidant capacity depletion ${ }^{10,11}$.

RIP is a therapeutic alternative that has been experimentally used to improve renal and liver function, and to decrease inflammatory changes after reperfusion. The RIP phenomenon was described in 1993 by Przyklenk et al. ${ }^{12}$, when they observed that brief ischemia-reperfusion episodes in the circumflex artery decreased myocardial infarction size caused by left anterior descending artery occlusion ${ }^{12}$.

To date, few clinical studies have been published on RIP, which offers protection to a distant organ or tissue $^{13,14}$. The mechanism by means of which a brief episode of ischemia-reperfusion of an organ offers protection against a subsequent ischemia episode in a distant organ or tissue it is still unclear. Three theories have been proposed to explain the RIP mechanisms: the neuronal hypothesis, the humoral hypothesis and a third hypothesis that proposes that transient ischemia and reperfusion of an organ or tissue cause a systemic protection response in the remote organ by suppressing inflammation and apoptosis by MAPK p38, ERK1/2 and JNK activation ${ }^{15,16}$. In experimental studies, the effect of RIP on the inflammatory response has been investigated by stimulating the transcription of anti-inflammatory and antiapoptotic genes ${ }^{15,17}$. The purpose of this study was to determine wether RIP modulates the mechanisms involved in ischemia-reperfusion injury in cadaveric donor liver transplant recipients through inflammatory mediators such as cytokines (IL-1, IL-6, FNT- $\alpha$ ), intracellular adhesion molecules (ICAM-1) and vascular epithelial growth factor (VEGF).

\section{Method}

\section{Patient population and study design}

Ten patients undergoing liver transplantation were included during the period of August 2013 to August 2015 at the University Hospital Dr. José Eleuterio González. Subjects of both genders, $>18$ and $<70$ years of age, undergoing non-urgent liver transplantation, were eligible to participate in this study after granting informed consent. The protocol was approved by the Ethics Committee of the University Hospital (TR12-002). 
The 10 recipients were divided in two groups: RIP group $(n=5)$ and control group without RIP $(n=5)$. The blood group was compatible between receptors and donors. RIP was induced in the donor by blood flow occlusion of both lower extremities by pneumatic tourniquet simultaneously placed on the upper third of both thighs for 10 minutes $(200 \mathrm{mmHg})$, which was subsequently deflated; this procedure was performed immediately before starting laparotomy. After liver graft procurement, which was carried out using the classical technique, the grafts were preserved with HTK solution (Custodiol ${ }^{\circledR}$ ) and, in the recipient, liver transplantation was performed using the piggyback technique The liver grafts were irrigated with normal saline and albumin through the portal vein to clear the preservation solution.

In both groups (RIP and control) blood samples $(15 \mathrm{~mL})$ were taken in the pre-transplant phases, 90 minutes post-perfusion, at 12, 24, 48 and 72 hours, and at 7, 15 and 30 days, and in the donors, before the RIP and at the beginning of laparotomy. At each phase, a blood sample was obtained for hematological and biochemical parameters determination, and for inflammatory response mediators; the blood sample was centrifuged at $3000 \mathrm{rpm}$ and the serum was aliquotted and stored at $-80{ }^{\circ} \mathrm{C}$ until its analysis. The immunosuppression regimen was induced with a steroid bolus during surgery prior to reperfusion and was maintained with tacrolimus, mofetil mycophenolate and steroids.

The variables assessed in the recipients were age, gender, liver disease etiology, MELD scale, ChildPugh score, cold ischemia time and anhepatic phase time. The primary efficacy endpoint of the study was the evaluation of inflammatory mediators and liver function modification through AST, ALT, total bilirubin and international normalized ratio 90 minutes after reperfusion and in the subsequent analyzed phases. The secondary endpoints were the incidence of primary graft failure and initial malfunctioning of the graft, the need for re-transplantation and 3-month graft survival.

\section{Determination of hematological and biochemical parameters}

Blood samples were used to determine hematological parameters in a Cell Dyn 1700 (Abbott Diagnostics, Abbott Park, IL, USA) and serum concentrations of the various biochemical markers were determined with standard commercial biochemical test kits, using the
ILAB Aries analyzer (Instrumentation Laboratory Headquarters Bedford, MA, USA) and DT6011 (Vitros Chemical System, Johnson and Johnson, USA).

\section{Pro-inflammatory Mediators}

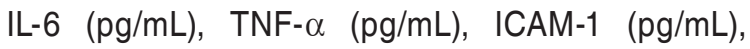
VEGF $(\mathrm{pg} / \mathrm{mL})$ and IL-1 $(\mathrm{pg} / \mathrm{mL})$ serum concentrations were determined using an immunoenzymatic assay kit specific to each mediator (Peprotech, Mexico).

\section{Statistical analysis}

The SPSS 22.0 statistical package (SPSS Inc. Software, Chicago, Illinois, USA) was used to analyze the data using Student's t-test to determine the comparison and the difference between groups. All values were expressed as means \pm standard deviation, and a $p$-value $<0.05$ was considered statistically significant.

\section{Results}

The donors were men $(4,40 \%)$ and women $(6$, $60 \%$ ), mean age was $41.3 \pm 14.6$ years, and neither group had expanded criteria; the causes of death were traumatic brain injury (46\%), stroke (45\%) and cerebral hypoxia (9\%).

The recipients were men $(6,60 \%)$ and women (4, $40 \%$ ), with mean age of $59.0 \pm 9.7$ years, body mass index of $26.1 \pm 5.7$, MELD mean value of 15 and Child Pugh classification B (9) and C (1). Liver cirrhosis etiology was alcoholic $(3,30 \%)$, non-alcoholic steatohepatitis $(3,30 \%)$, autoimmune $(1,10 \%)$, hepatitis $\mathrm{C}$ virus $(2,20 \%)$ and secondary biliary cirrhosis $(1,10 \%)$. Cold ischemia mean time was 4.1 hours, and mean anhepatic phase time was 49 minutes. There were no cases of primary graft failure, graft initial malfunction or acute rejection. Significant differences $(p<0.05)$ were found between groups in the following inflammatory mediators and phases: post-perfusion IL-6, at 24 hours and 72 hours; TNF- $\alpha$ at 7 days, 15 days and 30 days; and ICAM-1 in most phases: The values of each one of these mediators were higher in the group that received organs that underwent RIP; there was no significant difference in IL-1 and VEGF in all study phases (Table 1).

Regarding the assessed hematological parameters, only platelets showed mainly significant difference in some of the evaluated phases; however, higher values were observed in the RIP group since the 24-hour 


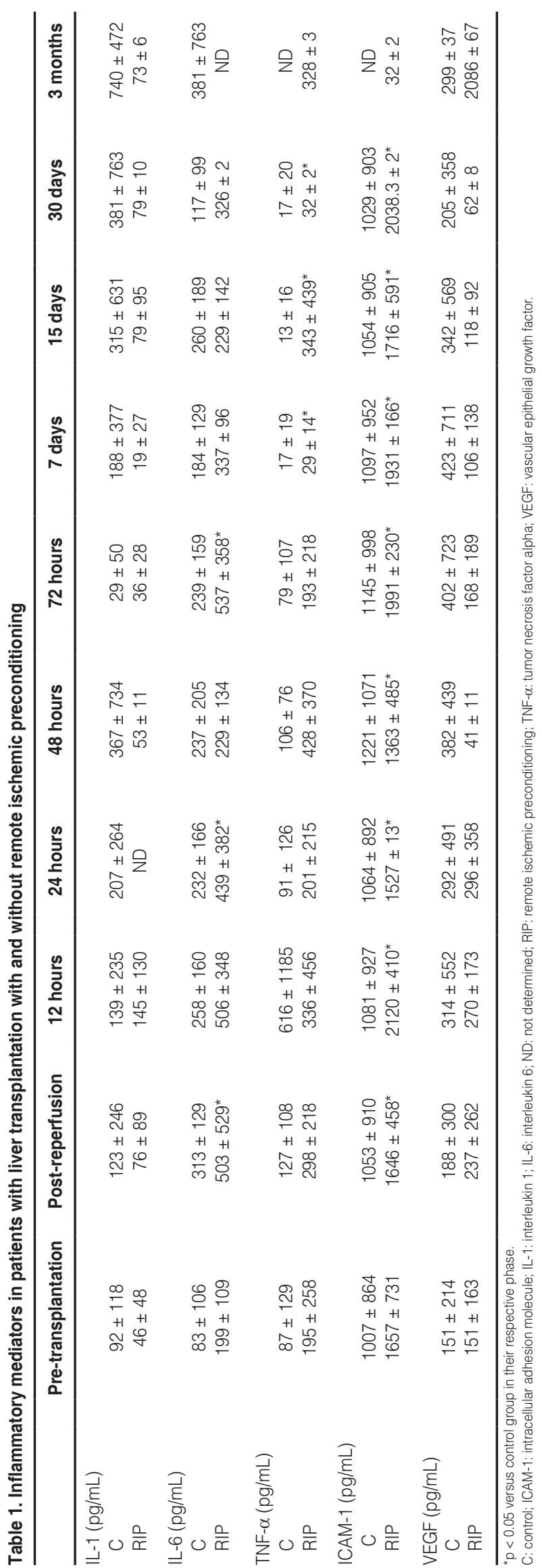

phase (Table 2). In the biochemical parameters, no significant difference was found in most phases (Table 3), but AST, ALT and alkaline phosphatase were higher at early phases of the study in the RIP group (from post-reperfusion to 72 hours) and subsequently they did decrease in the following phases, although the difference was only significant at 30 days. ALT and AST were normalized at 3 months in both groups and alkaline phosphatase only in the RIP group. Bilirubins significantly declined only in the last phases of the study in the RIP group (15 days to 3 months), and were normalized in this group at 30 days and thereafter (Table 4).

\section{Discussion}

Various surgical strategies to reduce ischemia-reperfusion injury have been assessed, and among them ischemic preconditioning has been shown to protect against ischemia-reperfusion injury ${ }^{18}$; however, the main limitation of this procedure is direct action on the target organ and its vascular structures, and thus, clinical application of ischemic preconditioning in liver transplantation has been limited due to unforeseen ischemic episodes and to possible ethical reasons. Instead, RIP can provide protection to distant organs without causing direct stress, and can also be applied prior to the start of ischemia in the target organ, during final ischemia or after reperfusion ${ }^{19}$.

Experimentally, RIP has been shown to be able to reduce ischemia-reperfusion liver injury ${ }^{4,20}$; however, there are still controversies regarding the duration of ischemia initial phase, reperfusion time and number of applied cycles ${ }^{21}$. In an experimental liver transplantation model, oxidative stress and inflammation have been shown to decrease by applying three 5-minute ischemia cycles prior to RIP22.

No clinical studies have been published about patients with cadaveric liver transplantation undergoing RIP; only one living donor liver transplantation has been reported where an ALT significant decrease was observed in the first 28 days of transplantation in recipients undergoing post-reperfusion RIP, as well as a significant increase in serum creatinine and glomerular filtration rate in the RIP group, which demonstrated that RIP decreased acute renal injury; no clinical benefit was observed with regard to early liver graft function, frequency of complications, hospital stay or mortality ${ }^{23}$.

In most clinical works where the ischemic preconditioning surgical technique has been used to reduce 


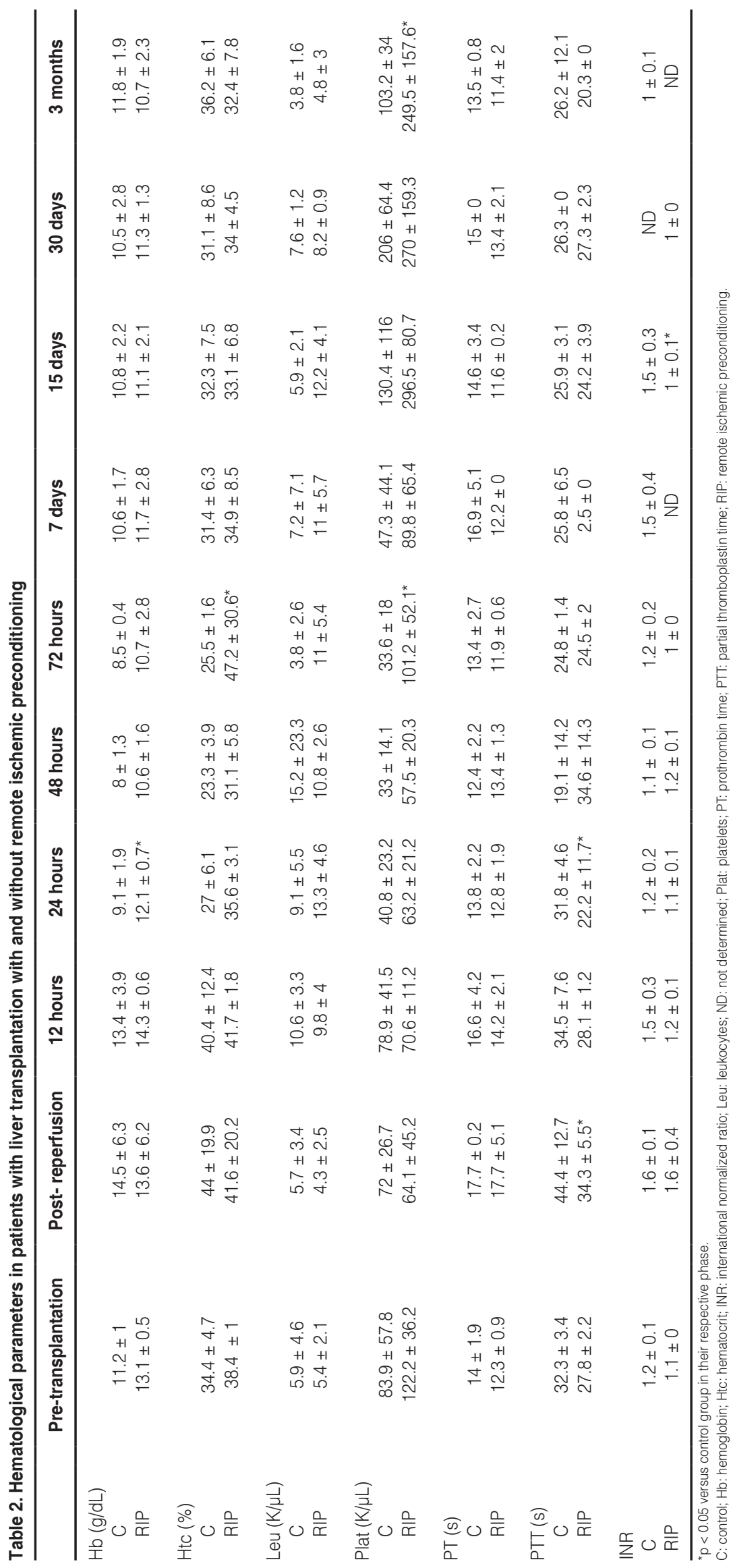




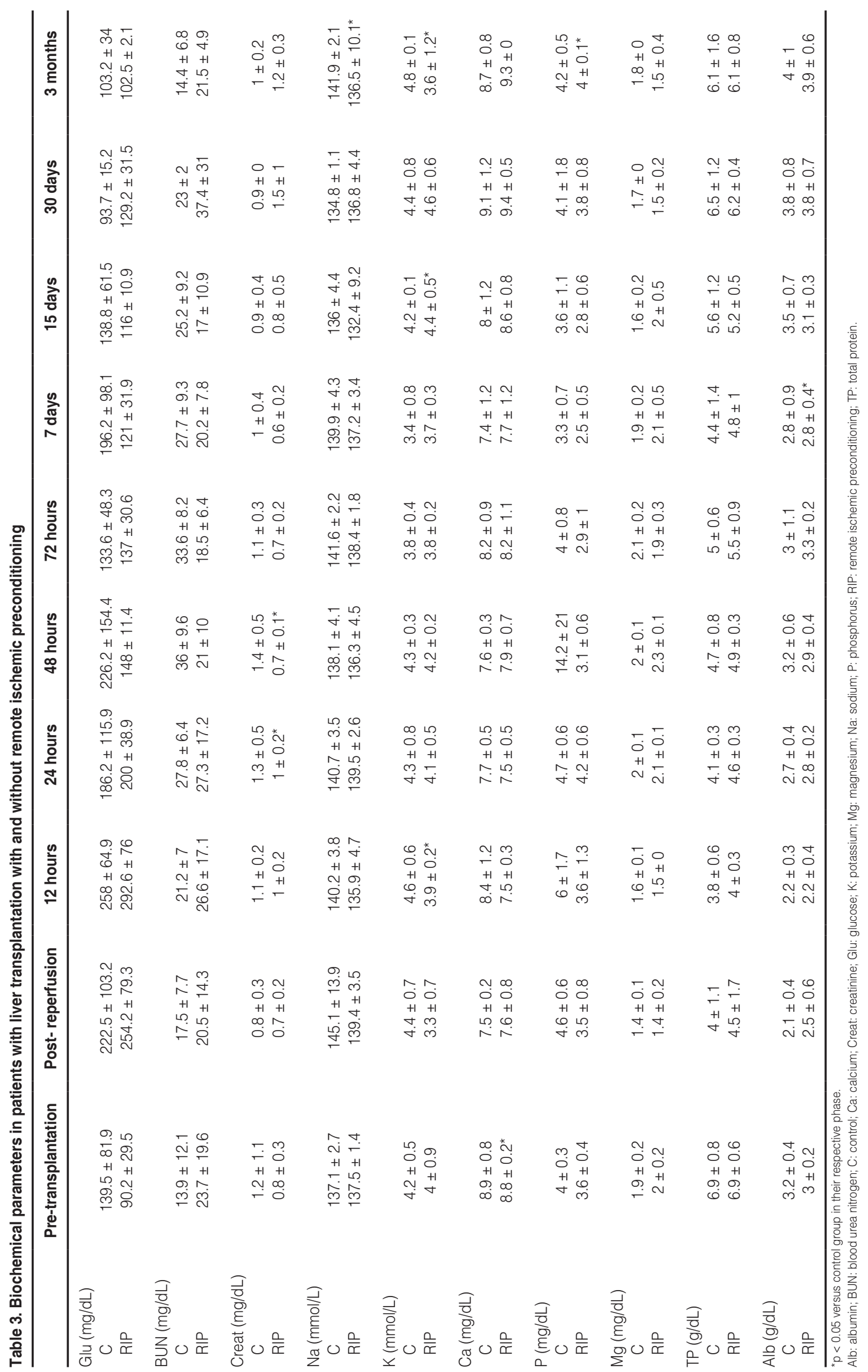




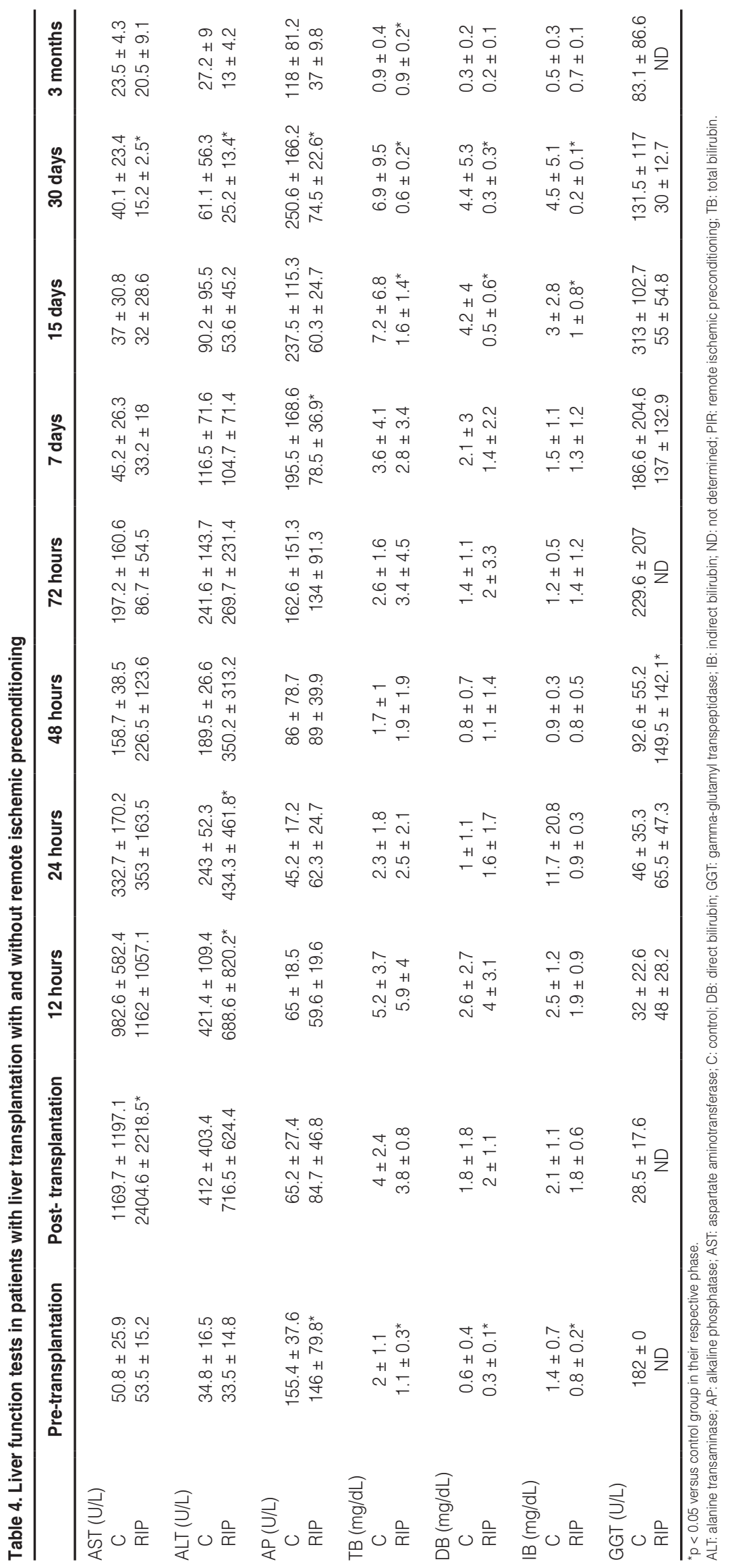


ischemia-reperfusion damage in liver transplantation, a decrease in aminotransferases has been reported ${ }^{8,9}$; however, in experimental studies, ischemic preconditioning attenuates ischemia-reperfusion liver injury by decreasing leukocyte infiltration, liver enzymes and apoptosis ${ }^{24,25}$. In the present study, a significant increase of said enzymes was observed at liver transplantation early stages, and thus we can deduce that, at this stage, RIP failed to improve ischemia-reperfusion injury, but in subsequent evaluated phases (after 72 hours) a better response was observed in the subjects who received a liver transplantation undergoing RIP.

Recently, in a murine model of liver transplantation with ischemic preconditioning, RIP or both, reducing ischemia-reperfusion injury was possible in preconditioned groups, since they had a significant decrease in transaminases, TNF- $\alpha$ and malondialdehyde, with less liver injury and apoptosis with regard to the control group, thus demonstrating a synergistic effect in the ischemic preconditioning plus RIP group ${ }^{26}$.

On the other hand, thrombocytopenia is highly common during liver transplantation reperfusion phase ${ }^{27,28}$, caused by the consumption and sequestration of platelets within liver sinusoids. The degree of platelet activation has been correlated with graft function; although platelets are thought to actively participate in the pathogenesis of ischemia-reperfusion injury, they may have beneficial effects during this phase by secreting substances such as serotonin, which participates in the repair of ischemic damage ${ }^{29}$. There is evidence suggesting that platelets have other non-hemostatic properties, by participating in inflammation, angiogenesis, regeneration and ischemia-reperfusion injury ${ }^{30}$. It has been experimentally demonstrated that RIP protects against partial liver ischemia through plateletderived serotonin, VEGF, IL-10 and matrix metalloproteinase $8^{30}$. In this study, a greater recovery of platelets count was found after 72 hours, which persisted up to 3 months in the group of patients receiving grafts undergoing RIP.

So far, the effect of RIP has only been reported in related live donor liver transplantation recipients. This is the first study where liver grafts undergoing RIP are compared with grafts not subjected to it in brain death donors. In this work, it was observed that, of the evaluated inflammatory mediators, only IL-6 appears to participate in the post-liver transplantation inflammatory response early stages, conversely to TNF- $\alpha$, whose participation is evident after the seventh posttransplantation day; however, ICAM-1 appears to be a more noticeable inflammatory mediator in the subjects who received grafts with RIP, since this molecule rose significantly since the initial phase after liver transplantation until 30 days, and was normalized only until 3 months.

Of note, along with inflammatory mediators, liver enzymes AST, ALT and alkaline phosphatase rise considerably in the post-transplantation immediate phases and decrease faster in recipients with RIP after 72 hours, with this effect being maintained until 15 days and recovery to normal values being achieved more quickly in those subjects, but not in the group of recipients without RIP. In both study groups, there was no primary failure or graft rejection during the evaluated follow-up, but in the group that underwent RIP, a faster recovery was observed to be achieved both in inflammatory parameters and in some biochemical parameters associated with an improvement in the liver function, and for this reason, we consider that the procedure favors the reduction of ischemia-reperfusion damage in liver grafts, and that increasing the number of patients is necessary, as well as defining to which mechanisms is this improvement attributed.

\section{Funding}

CONACYT-México (2012-1-182653) and PAICYT-UANL.

\section{Conflict of interests}

The authors declare that there are no conflicts of interest.

\section{References}

1. Teoh N, De la Pena A, Farrell G. Hepatic ischemic preconditioning in mice is associated with activation of NF- $\mathrm{kB}$, p38 kinase, and cell cycle entry. Hepatology. 2002;36:94-102.

2. Ramírez $P$, Marín JM, Piñero A, Chávez-Cartaya R, Parrilla P. Investigación experimental aplicada a la clínica: isquemia-reperfusión hepática. Cir Esp. 2000;67:281-91.

3. Jaeschke $\mathrm{H}$. Molecular mechanisms of hepatic ischemia-reperfusion injury and preconditioning. Am J Physiol Gastrointest Liver Physiol. 2003;284:15-26.

4. Wang F, Birch SE, He R, Tawadros P, Szaszi K, Kapus A, et al. Remote ischemic preconditioning by hindlimb occlusion prevents liver ischemic/reperfusion injury: the role of High Mobility Group-Box 1. Ann Surg. 2010;251:292-9

5. Selzner M, Selzner N, Jochum W, Graf R, Clavien PA. Increased ischemic injury in old mouse liver: an ATP $₫$ dependent mechanism. Liver Transpl. 2007;13:382-90.

6. Selzner N, Rudiger H, Graf R, Clavien PA. Protective strategies against ischemic injury of the liver. Gastroenterology. 2003;125:917-36.

7. Peralta C, Serafín A, Fernández-Zabalegui L, Wu ZY, Roselló-Catafau J. Liver ischemic preconditioning: a new strategy for the prevention of ischemia-reperfusion injury. Transplant Proc. 2003;35:1800-2.

8. Azoulay D, Del Gaudio M, Andreani P, Ichai P, Sebag M, Adam R, et al. Effects of 10 minutes of ischemic preconditioning of the cadaveric liver on the graft's preservation and function: the ying and the yang. Ann Surg. 2005;242:133-9.

9. Cescon M, Grazi GL, Grassi A, Ravaioli M, Vetrone G, Ercolani G, et al. Effect of ischemic preconditioning in whole liver transplantation from deceased donors. A pilot study. Liver Transpl. 2006;12:628-35. 
10. Costa FL, Yamaki VN, Gonçalves TB, Coelho JV, Percário S, Brito MV. Combined remote ischemic perconditioning and local postconditioning on liver ischemia-reperfusion injury. J Surg Res. 2014;192:98-102.

11. Eltzschig HK, Eckle T. Ischemia and reperfusion - from mechanism to translation. Nat Med. 2011;17:1391-401.

12. Przyklenk K, Bauer B, Ovize M, Kloner RA, Whittaker P. Regional ischemic' preconditioning protects remote virgin myocardium from subsequent sustained coronary occlusion. Circulation. 1993;87:893-9.

13. Wu J, Feng X, Huang H, Shou Z, Zhang X, Wang R, et al. Remote ischemic conditioning enhanced the early recovery of renal function in recipients after kidney transplantation: a randomized controlled trial. J Surg Res. 2014;188:303-8.

14. Nicholson ML, Pattenden CJ, Barlow AD, Hunter JP, Lee G, Hosgood SA. A double blind randomized clinical trial of remote ischemic conditioning in live donor renal transplantation. Medicine. 2015;94:e1316.

15. Le Page S, Prunier F. Remote ischemic conditioning: current clinical perspectives. J Cardiol. 2015;66:91-6.

16. Hausenloy DJ, Yellon DM. Remote ischemic preconditioning: underlying mechanisms and clinical application. Cardiovasc Res. 2008;79:377-86.

17. Konstantinov IE, Arab S, Li J, Coles JG, Boscarino C, Mori A, et al. The remote ischemic preconditioning stimulus modifies gene expression in mouse myocardium. J Thorac Cardiovasc Surg. 2005;130:1326-32.

18. Koneru B, Fisher A, He Y, Klein KM, Skurnick J, Wilson DJ, et al. Ischemic preconditioning in deceased donor liver transplantation: a prospective randomized clinical trial of safety and efficacy. Liver Transpl. 2005;11:196-202.

19. Jia JJ, Li JH, Jiang L, Lin BY, Wang L, Su R, et al. Liver protection strategies in liver transplantation. Hepatobiliary Pancreat Dis Int. 2015;14:34-42.

20. Czigany Z, Turoczi Z, Bulhardt O, Hegedus V, Lotz G, Rakonczay Z, et al Remote ischemic conditioning: short-term effects on rat liver ischemic-reperfusion injury. Orv Hetil. 2012;153:1579-87.
21. Skyschally A, van Caster P, lliodromitis EK, Schulz R, Kremastinos DT, Heusch G. Ischemic postconditioning: experimental models and protocol algorithms. Basic Res Cardiol. 2009;104:469-83.

22. Jia J, Li J, Jiang L, Zhang J, Chen S, Wang L, et al. Protective effect of remote limb ischemic perconditioning on the liver grafts of rats with a novel model. PLoS One. 2015;10:e0121972.

23. Kim WH, Lee JH, Ko JS, Min JJ, Gwak MS, Kim GS, et al. Effect of remote ischemic postconditioning on patients undergoing living donor liver transplantation. Liver Transpl. 2014;20:1383-92.

24. Jin LM, Liu YX, Zhou L, Xie HY, Feng XW, Li H, et al. Ischemic preconditioning attenuates morphological and biochemical changes in hepatic ischemia/reperfusion in rats. Pathobiology. 2010;77:136-46.

25. Yan S, Jin LM, Liu YX, Zhou L, Xie HY, Zheng SS. Outcomes and mechanisms of ischemic preconditioning in liver transplantation. Hepatobiliary Pancreat Dis Int. 2010;9:346-54.

26. Li DY, Shi XJ, Li W, Sun XD, Wang GY. Ischemic preconditioning and remote ischemic preconditioning provide combined protective effect against ischemia/reperfusion injury. Life Sci. 2016;1:76-80.

27. Novaković-Anucin S, Gnip S, Canak V, Jurisić D, Radović P, Erdeljan S, et al. Laboratory monitoring of the haemostatic system changes during orthotopic liver transplantation. Srp Arh Celok Lek. 2013;141:608-14.

28. Hartmann M, Szalai C, Saner FH. Hemostasis in liver transplantation: pathophysiology monitoring and treatment. World J Gastroenterol. 2016;22:1541-50.

29. Pereboom IT, Lisman T, Porte RJ. Platelets in liver transplantation: friend or foe? Liver Transpl. 2008;14:923-31.

30. Tripodi A, Salerno F, Chantarangkul V, Clerici M, Cazzaniga M, Primignani $\mathrm{M}$, et al. Evidence of normal thrombin generation in cirrhosis despite abnormal conventional coagulation tests. Hepatology. 2005;41:553-8. 